\title{
Ceviz, Fındık ve Yerfıstığı Kabuklarını Kullanarak Sipermetrinin Çevreden Uzaklaştırılması
}

\author{
Deniz TÜRKÖZ ALTUĞ $\breve{G}^{*}$ \\ Süleyman Demirel Üniversitesi, Isparta Sağlık Hizmetleri Meslek Yüksekokulu, Isparta, Türkiye
}

(ORCID: 0000-0002-1861-6263)

\begin{abstract}
$\ddot{\mathbf{O} z}$
Dünya nüfusunun artması çevre kirliliğini de beraberinde getirmektedir. Çevrenin doğallığını bozabilecek herhangi bir müdahale havaya, toprağa ve suya etki ederek tüm ekosistemdeki canlılara ulaşabilmektedir. Bu yüzden çevre kirliliğini en aza indirebilmek çok güncel bir konudur. Bir taraftan artan nüfusun gıda ihtiyacını karşılayabilmek için kimyasallar yardımıyla üretilen ürünün verimi artarken diğer taraftan hedef dışındaki bölgelere de bu kimyasallar ulaşabilmektedir. Hedef dışı bölgelere ulaşan kimyasallar canlılar üzerine olumsuz etkiler oluşturabilmektedir. Bu çalışmada; Türkiye'de ve dünyada tarımcıllkta ürünlerin böcek istilasını engellemede yaygın olarak kullanılan sipermetrinin, ceviz, findık ve yerfistığı kabuklarını kullanarak, toprak veya suya geçişine engel olmak için laboratuvar ortamında yapılan deneylerle çevrenin korunabileceği konusunda çalışılmıştır. Ceviz, findık ve yerfıstığı kabuklarının gözenekli yapısı bu kimyasalların toprağa ve suya geçmeden önce adsorbe olabileceğini FTIR ve SEM-EDS spektroskopik yöntemlerini kullanarak gösterilmiştir. Böylece masrafsız bir yöntemle sipermetrini çevreye dağılmadan önce doğal malzemeler olan ceviz, findık ve yerfisttğı kabuklarının gözenekli yapısına hapsederek hedef dışı bölgelere ulaşmasına engel olunabilecektir.
\end{abstract}

Anahtar kelimeler: Sipermetrin, Ceviz Kabuğu, Fındık Kabuğu, Yerfıstığı Kabuğu, FTIR, SEM-EDS.

\section{Removing Cypermethrin from the Environment Using Walnut, Hazelnut and Peanut Shells}

\begin{abstract}
The increase in the world population has bring along environmental pollution. An intervention that can disturb the naturalness of the environment can be reach the living things in the entire ecosystem by affecting the air, soil and water. Therefore, minimizing environmental pollution is a very topical issue. On the one hand, the yield of the product produced with the help of chemicals increases in order to meet the food needs of the increasing population, on the other hand, these chemicals can reach the regions outside the target. Chemicals reaching non-target areas can have negative effects on living things. In this study; widely used of cypermethrin, in order to prevent insect infestation of the products in agriculture in Turkey and the world, with the experiment conducted in the laboratory condition using walnut, nuts and peanut shells to able to prevent from the environment passing of to the soil and water has been studied. The porous structure of walnut, hazelnut and peanut shells has been shown to be able to adsorb these chemicals using FTIR and SEM-EDS spectroscopic technical methods before they enter the soil and water. Thus, with an inexpensive method, it can be prevented from reaching non-target areas by trapped the porous structure of the natural materials walnut, hazelnut and peanut shells before dispersing of the cypermethrin to the environment.
\end{abstract}

Keywords: Cypermethrin, Walnut Shell, Hazelnut Shell, Peanut Shell, FTIR, SEM-EDS.

\section{Giriş}

Gerek tıp alanında gerekse bilim ve teknolojideki gelişmeler insan ortalama hayatının uzamasına böylece dünya nüfusunun artmasına sebep olmuştur. Çiftçiler artan nüfusun temel ihtiyacı olan gıda

*Sorumlu yazar: denizturkoz@sdu.edu.tr

Geliş Tarihi: 28.01.2021, Kabul Tarihi: 12.04.2021 
gereksinimini karşılayabilmek ve kısıtlı tarım alanlarında yetiştirdikleri ürünün verimini arttırabilmek için kimyasallardan destek almaktadır [1]. Böylece ürünler büyürken daha az deforme olur ve üretilen ürünün miktarı ve kalitesi artabilmektedir. Ancak yapılan araştırmalar bu kimyasalların sadece ürünü korumakla kalmayıp uygulanan çevreninde bu ilaçlanmadan etkilediğini gösterdi [2-4]. Gerek toprakta gerekse tarım alanına yakın bölgelerdeki su kaynaklarında bu zirai ilaçların kalıntılarına rastlanmaktadır [5-9]. Yani çevreye yayılan bu ilaçlar doğal olaylarla istenmeyen bölgelere taşınabilmektedir.

Sipermetrin $(\mathrm{CM})$ tarımla uğraşan kişilerin ürettikleri ürünleri böcek istilasından koruyabilmek için dünya genelinde sik kullandıkları zirai bir pestisittir [10, 11]. CM'nin kimyasal formülü; $\mathrm{C}_{22} \mathrm{H}_{19} \mathrm{Cl}_{2} \mathrm{NO}_{3}$ şeklindedir [12]. Molekül yapıs1 Şekil 1'de gösterilmektedir. CM sentetik bir pyrethroiddir [11] ve canlılar üzerinde kanserojen etkileri vardır [13]. Bu özelliğinden dolayı çevreden uzaklaştırılması oldukça önem arz etmektedir.<smiles>CC1(C)C(C=CCl)C1C(=O)OC(C#N)c1cccc(Oc2ccccc2)c1</smiles>

Şekil 1. Sipermetrinin molekül yapısı

Bu çalışmada kullanılan atık ceviz, fındık ve yerfıstığı kabukları literatürde çeşitli şekillerde değerlendirilmiştir. Örneğin; aktive edilen ceviz kabukları, boyar maddelerin adsorpsiyonu için kullanılmıştır [14]. Fındık ve ceviz kabukları enerji üretme amaçlı kullanılmıştır [15]. Metilen mavisinin sulu çözeltiden uzaklaştırılmasında ceviz kabukları kullanılmıştır [16, 17]. Ceviz kabukları kompozitleştirilmiş laktik asitlerde dolgu malzemesi olarak kullanılması konusunda çalışmada vardır [18]. Seliloz elde etmek için ceviz kabuğu atıkları kullanılmıştır [19]. Fındık kabuklarının aktif karbonu kullanılarak sulu çözeltilerden bakır iyonunun uzaklaştırılması çalışılmıştır [20-22]. Sulu çözeltilerden aniyonik boyanın, $\mathrm{Pb}$ iyonunun ve organik boyaların uzaklaştırmak için yerfıstığı kabuğu kullanılmışır [23-26].

$\mathrm{Bu}$ çalışmada ise $\mathrm{CM}$ nin çevreden uzaklaştırılmasında ceviz, findık ve yerfıstığı kabuklarının gözenekli yapıya sahip olması özelliğinden faydalanarak hiçbir işlem görmeden yani; ham hali kullanılmıştır.

\section{Materyal ve Metot}

Bu çalışmada, adsorban olarak ceviz, findık ve yerfıstı̆̆ kabukları kullanılmıştır. Ayrıca adsorbat olarak da zirai ilaç satıcısından alınan Hektaş LTD tarafından pazarlanan $\mathrm{CM}\left(\mathrm{C}_{22} \mathrm{H}_{19} \mathrm{Cl}_{2} \mathrm{NO}_{3}\right)$ kullanılmıştır.

\subsection{FTIR Spektroskopisi}

Saf ceviz, fındık ve yerfıstığı kabukları ve CM ile muamele edilmiş ceviz, fındık ve yerfıstığı kabuklarına ait FTIR spektrumları KBr pellet tekniği kullanılarak Süleyman Demirel Üniversitesi, Yenilikçi Araştırma ve Uygulama Merkezi’nde 4000-400 $\mathrm{cm}^{-1}$ aralığında alınmıştır.

\subsection{SEM-EDS}

Saf ceviz, findık ve yerfistığı kabukları ve CM ile muamele edilmiş ceviz, findık ve yerfıstığ kabuklarına ait SEM görüntüleri ve EDS analizleri Süleyman Demirel Üniversitesi, Yenilikçi Araştırma ve Uygulama Merkezi'nde alınmıştır.

\subsection{Adsorpsiyon Deneyi}

Ceviz, findık ve yerfıstığı kabukları safsızlıklardan arındırmak için şebeke suyu kullanılarak dış yüzeyleri temizlendi. Daha sonra ögütücüde toz haline getirildi. Bütün bu işlemlerin ardından saf su ile 
birlikte ultrasonik banyoda 20 dakika yıkandı ve kaba filtre kağıdıyla süzüldü ve kurutuldu. Kuruyan numunelerden 0,5 g tartılarak beher içerisine alındı. Başka bir beher içerisinde $1 \mathrm{~mL} \mathrm{CM} \mathrm{ve} 3 \mathrm{~mL}$ saf su karıştırıcıda 2 saat boyunca karıştırıldıktan sonra diğer beherdeki toz numunelerin üzerine eşit miktarda döküldü ve manyetik karıştırıııda 72 saat boyunca karıştırıldı. Ardından filtre kağıdından süzülerek tekrar saf su ile yıkandı, süzüldü ve kurutuldu. Kurutma işleminden sonra saf ve adsorplanmış örneklerin FTIR spektrumları ve SEM görüntüleri alındı ve EDS analizleri yapıldı.

\section{Bulgular ve Tartışma}

\subsection{FTIR Spektroskopisi}

Örneklerin saf hallerini ve adsorplama işleminden sonraki değişiklikleri gözlemlemek için FTIR spektroskopisi kullanıldı. Şekil 2'de saf ve CM ile muamele edilmiş örneklerin FTIR spektrumları görülmekte. Bu spektrumlardan oluşturulmuş veriler Tablo 1'de sunulmuştur. Ayrıca CM ye ait karakteristik pikler ile CM ile muamele edilmiş örneklere ait FTIR atamaları görülmektedir. Tablo 1 incelendiğinde, CM ye ait karakteristik piklerin neredeyse tamamı, CM ile muamele edilmiş ceviz, fındık ve yerfıstığı kabuklarında görülmektedir.

Tablo 1 incelendiğinde; CM de gözlenen $1742 \mathrm{~cm}^{-1}$, deki titreşim bandı karbonil gerilmesindeki $\mathrm{C}=\mathrm{O}$ titreşiminden kaynaklandığ 1 ve aynı grup titreşimin saf ceviz, findık ve yerfıstığı kabuğunda da olduğu, $1589 \mathrm{~cm}^{-1}$ de gözlenen titreşim bandı kloraalkendeki $\mathrm{C}=\mathrm{C}$ titreşiminden ve 1487 ve $1455 \mathrm{~cm}^{-1}$ titreşim bandlarının ise $\mathrm{R}-\mathrm{CH}_{2}-\mathrm{CN}$ yapısındaki deki $\mathrm{CH}_{2}$ deformasyon titreşim kaynaklandığ düşünülmektedir [11]. CM adsorbe edilmiş örneklerde $1589 \mathrm{~cm}^{-1}$ civarında omuz band1, $1488 \mathrm{~cm}^{-1}$ civarında yeni oluşmuş bir band ve $1453 \mathrm{~cm}^{-1}$ civarında zayıf omuz bandı olarak görülmektedir. CM de $1078 \mathrm{~cm}^{-1}$ de ki titreşim band, $(\mathrm{C}=\mathrm{O})$-O- titreşiminden kaynaklandığ 1 düşünülmektedir [11]. $\mathrm{CM}$ ile muamele edilmiş ceviz ve findık kabuklarında $1074 \mathrm{~cm}^{-1}$ de yeni oluşmuş orta şiddetteki bir band olarak gözlenmekte iken yerfıstığı kabuğunda gözlenmemektedir. CM'de gözlenen $1243 \mathrm{~cm}^{1}$ 'deki band difenileterin aril-O titreşiminden, C-O-C düzlem dişı titreşimi ve halka titreşiminden kaynaklandığı, ayrıca $1124 \mathrm{~cm}^{-1}$, de görülen band HCC düzlem içi bükülme bandı ilgili olduğu düşünülmektedir [28]. CM deki $921 \mathrm{~cm}^{-1}$ deki band terminal dihalovinil grubunun asimetrik sallanmasından bağl1 olduğu ve CM ile muamele edilmiş örneklerde zayıf band olarak $923 \mathrm{~cm}^{-1}$ civarında ortaya çıkmıştır [27]. CM de; Sayklopropen halkasının deformasyon titreşimine ait olan $873 \mathrm{~cm}^{-1}$ de ki band CM adsorbe edilmiş örneklerde $884 \mathrm{~cm}^{-1}$ civarında yeni oluşan zayıf band olarak görülmektedir [27]. CM de $769 \mathrm{~cm}^{-1}$ deki güçlü C-H deformasyon titreşim band1, CM adsorbe edilmiş örneklerde $780 \mathrm{~cm}^{-1}$ civarında zayıf yeni bir band olarak görülmektedir [12]. CM de $691 \mathrm{~cm}^{-1}$ deki band $\mathrm{C}-\mathrm{Cl}$ gerilim bandına ait olup CM adsorplanmış örneklerde yeni bir band olarak $693 \mathrm{~cm}^{-1}$ civarında ortaya çıkmıştır [29, 30].

Tablo 1. CM ye ait ve CM ile muamele edilmiş ceviz, findık ve yerfıstığı kabuklarına ait FTIR atamaları

\begin{tabular}{ccccc}
\hline Atamalar & $\mathrm{CM}$ & $\begin{array}{c}\text { CM ile muamele } \\
\text { edilmiş Ceviz Kabuğu }\end{array}$ & $\begin{array}{c}\text { CM ile muamele edilmiş } \\
\text { Findik Kabuğu }\end{array}$ & $\begin{array}{c}\text { CM ile muamele edilmiş } \\
\text { Yerfistığ Kabuğu }\end{array}$ \\
\hline$v(\mathrm{CH})$ & $3029 \mathrm{o}$ & $2959 \mathrm{om}$ & $2958 \mathrm{om}$ & - \\
$v(\mathrm{CH})$ & $2928 \mathrm{~g}$ & $2930 \mathrm{~g}$ & $2926 \mathrm{~g}$ & $2925 \mathrm{~g}$ \\
$v(\mathrm{CH})$ & $2875 \mathrm{z}$ & $2866 \mathrm{om}$ & $2876 \mathrm{om}$ & $2875 \mathrm{om}$ \\
$v(\mathrm{C}=\mathrm{O})$ & $1742 \mathrm{~g}[11]$ & $1743 \mathrm{~g}$ & $1742 \mathrm{~g}$ & $1740 \mathrm{~g}$ \\
$v(\mathrm{C}=\mathrm{C})$ & $1589 \mathrm{~g}[11]$ & $1589 \mathrm{om}$ & $1592 \mathrm{om}$ & $1584 \mathrm{om}$ \\
$v(\mathrm{C}=\mathrm{C})$ & $1487 \mathrm{~g}[11]$ & $1488 \mathrm{o}$ & $1487 \mathrm{z}$ & $1491 \mathrm{z}$ \\
$\delta(\mathrm{CH})$ & $1455 \mathrm{o}[11]$ & $1451 \mathrm{~g}$ & $1453 \mathrm{o}$ & $1458 \mathrm{o}$ \\
$v(\mathrm{C}-\mathrm{O}-\mathrm{C})$ & $1243 \mathrm{~g}[27]$ & $1247 \mathrm{~g}$ & $1247 \mathrm{~g}$ & $1263 \mathrm{~g}$ \\
$\beta(\mathrm{HCC})$ & $1124 \mathrm{~g}[28]$ & $1116 \mathrm{o}$ & $1116 \mathrm{o}$ & - \\
$v((\mathrm{C}=\mathrm{O})-\mathrm{O})$ & $1078 \mathrm{o}[11]$ & $1074 \mathrm{o}$ & $1074 \mathrm{o}$ & $924 \mathrm{z}$ \\
$\tau(\mathrm{HCCC})$ & $921 \mathrm{z}[27]$ & $923 \mathrm{z}$ & $922 \mathrm{z}$ & $896 \mathrm{z}$ \\
$\delta(\mathrm{HCC})$ & $873 \mathrm{z}[27]$ & $884 \mathrm{z}$ & $883 \mathrm{z}$ & $779 \mathrm{z}$ \\
$\delta(\mathrm{CH})$ & $769 \mathrm{~g}[12]$ & $780 \mathrm{z}$ & $782 \mathrm{z}$ & $693 \mathrm{z}$ \\
$v(\mathrm{C}-\mathrm{Cl})$ & $691 \mathrm{~g}[29,30]$ & $693 \mathrm{z}$ & $692 \mathrm{z}$ & \\
\hline
\end{tabular}

$v$ : simetrik gerilme, $\delta$ : deformasyon, $\tau$ : burulma, $\beta$ : düzlem içi bükülme, g: güçlü, o: orta, z: zayıf, om: omuz, gn: geniş 

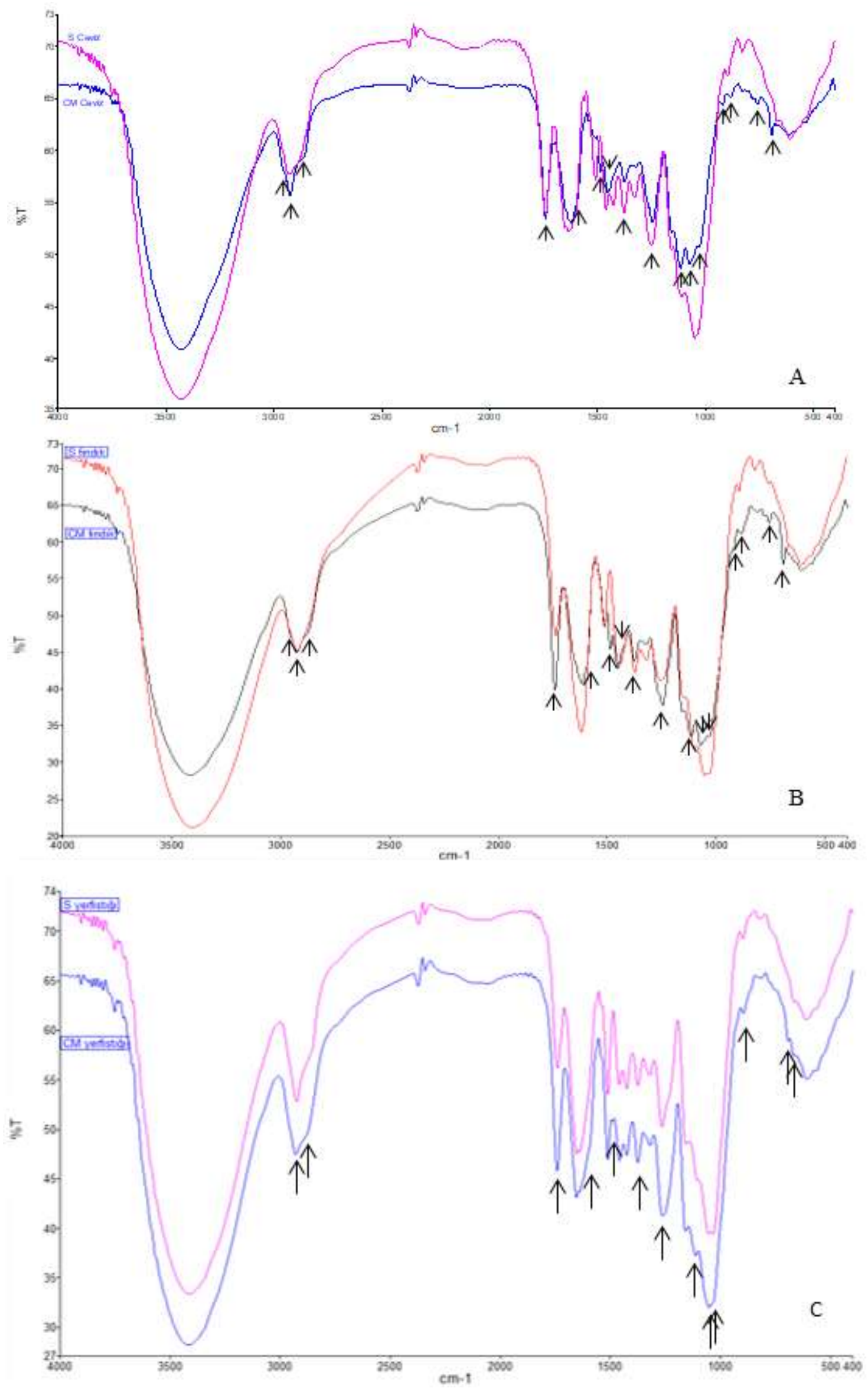

Şekil 2. A) Saf ceviz kabuğu ve CM adsorbe edilmiş ceviz kabuğu B) Saf findık kabuğu ve CM adsorbe edilmiş findık kabuğu C) Saf yerfistığı kabuğu ve CM adsorbe edilmiş yerfistığı kabuğuna ait FTIR spektrumları 


\subsection{SEM-EDS}

Ceviz, findık ve yerfıstığı kabukları CM ile muamele edildikten sonra örneklere ait topografik değişimi görüntülemek için SEM kullanıldı. Saf örnekler ile CM adsorbe edilmiş örneklerin görüntüleri Şekil 3'de sunulmuştur.

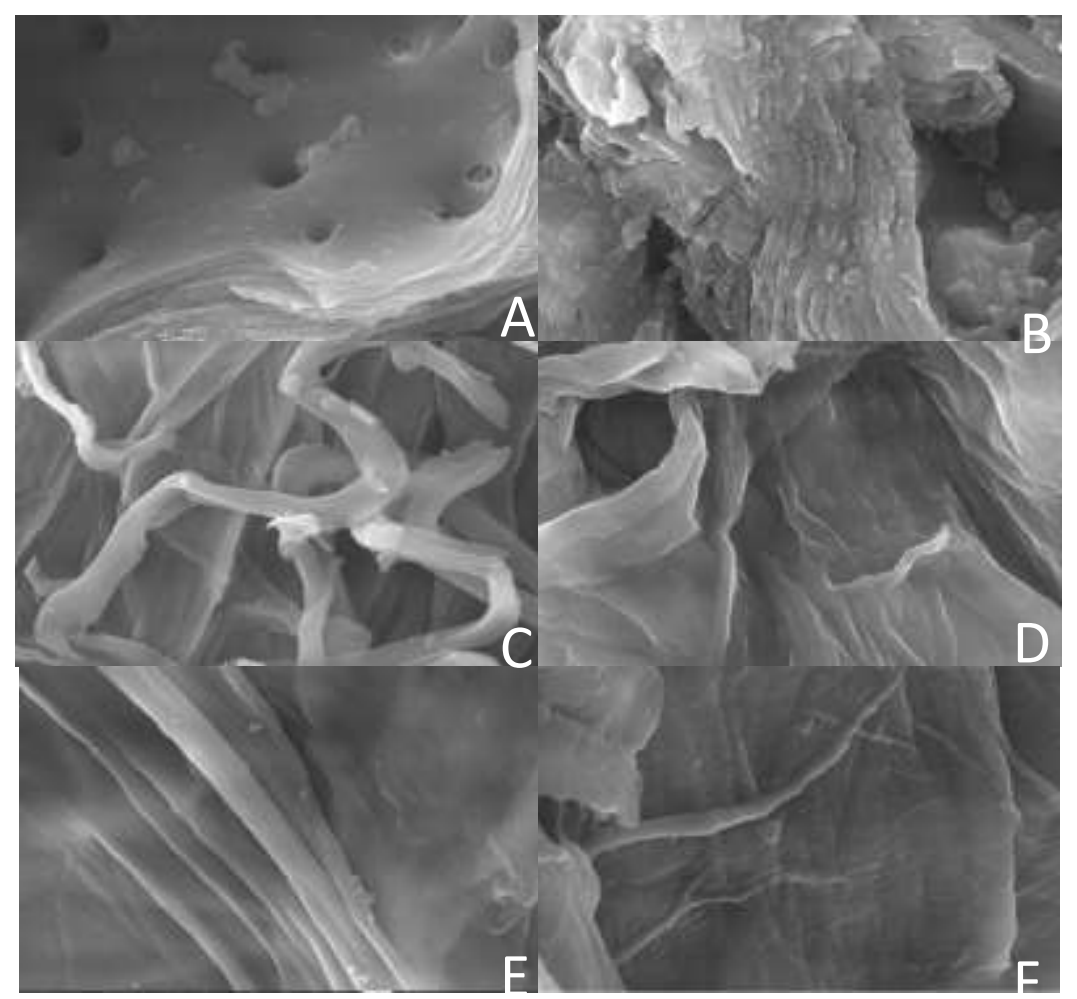

Şekil 3. A) Saf ceviz kabuğu B) CM adsorbe edilmiş ceviz kabuğu (20000 defa büyütülmüş görüntü) C) Saf fındık kabuğu D) CM adsorbe edilmiş fındık kabuğu (20000 defa büyütülmüş görüntü) E) Saf yerfıstığı kabuğu F) CM adsorbe edilmiş yerfistığı kabuğu (20000 defa büyütülmüş görüntü)

Şekil 3'de görünen görüntüler için koyu renkler çukurları, aydınlık renkler ise yükseklikleri göstermektedir. Saf ceviz, findık ve yerfıstığı görüntüleri Şekil 3-A-C ve E'de gösterilmektedir. Her birindeki görüntülerde gözenekler belirgin bir şeklide görülmektedir. Şekil 3-B-D ve F'de CM adsorplanmış ceviz, findık ve yerfıstı̆̆ kabuklarına ait görüntüler sunulmuştur. Örneklerin saf halleri incelendiğinde; ceviz kabuklarında düzenli silindirik gözenekler gözlenirken, findık kabuklarında lifli bir görüntü bulunmaktadır. Yerfıstığı kabuğunda ise oluklu yapıya sahip gözenekleri bulunmaktadır. Adsorplama işleminden sonra tüm numunelerin saf hallerinde bulunan gözenekleri dolarak kabuklar üzerinde düzleşmeler görülmektedir. Saf örnekler ve $\mathrm{CM}$ adsorbe edilmiş örneklerde bulunan elementleri incelemek için EDS analizleri yapılmıştır. Bu örneklerdeki elementlerin \%Ağırlık olarak sonuçları Tablo 2'de sunulmuştur.

Tablo 2. Saf ceviz, findık ve yerfıstığı kabukları ile CM ile muamele edilmiş ceviz, findık ve yerfistığı kabuklarının SEM-EDS sonuçları (Ağırlık\%)

\begin{tabular}{ccccccc}
\hline Ceviz & $\begin{array}{c}\text { CM ile muamele } \\
\text { kabuğu }\end{array}$ & $\begin{array}{c}\text { Findik } \\
\text { kabuğu } \\
\text { kabuğu }\end{array}$ & $\begin{array}{c}\text { CM ile muamele } \\
\text { edilmiş Findık } \\
\text { kabuğu }\end{array}$ & $\begin{array}{c}\text { Yerfistı̆̆ } \\
\text { kabuğu }\end{array}$ & $\begin{array}{c}\text { CM ile muamele } \\
\text { edilmiş yerfistı̆̆ } \\
\text { kabuğu }\end{array}$ \\
\hline $\mathrm{C}$ & 49,66 & 59,67 & 68,21 & 54,75 & 56,12 & 56,43 \\
$\mathrm{O}$ & 44,20 & 35,84 & 27,16 & 37,07 & 40,88 & 41,04 \\
$\mathrm{Mg}$ & 0,48 & 0,21 & 0,21 & 0,45 & 0,25 & 0,26 \\
$\mathrm{Al}$ & 4,20 & 1,99 & 0,89 & 4,71 & 1,94 & 1,24 \\
$\mathrm{Cl}$ & - & 0,68 & - & 1,94 & - & 0,7 \\
$\mathrm{~K}$ & - & - & 1,78 & 0,17 & - & - \\
$\mathrm{Ca}$ & 1,46 & 1,61 & 1,74 & 0,92 & 0,81 & 0,34 \\
\hline
\end{tabular}


Tablo 2'deki SEM-EDS sonuçları incelendiğinde; örneklerin hepsinde $\mathrm{C}, \mathrm{O}, \mathrm{Mg}, \mathrm{Al}$ ve $\mathrm{Ca}$ elementlerine rastlanmıştır. Sadece findıkta bu elementlere ek olarak K elementi bulunmaktadır. Ayrıca $\mathrm{CM}$ ile muamele edilmiş örneklerin herbirinde $\mathrm{Cl}$ elementi gözlenmektedir. $\mathrm{Cl}$ elementinin varlığı; $\mathrm{CM}$ nin yapısında bulunan $\mathrm{Cl}$ elementinden dolayıdır. $\mathrm{Cl}$ elementinin en çok \% Ağırlık olarak findık kabuğunda bulunması, SEM görüntüleri ile karşılaştırıldığında gözenek genişliklerinin en büyük findık kabuğunda olmasından kaynaklandığı düşünülmektedir.

\section{Sonuç ve Öneriler}

$\mathrm{Bu}$ çalışmada; tarımcılıkta kullanılan sipermetrinin hedef dışı bölgelere ulaşmasını azaltabilmek için ceviz, findık ve yerfıstığ kabukları kullanıldı. Çünkü bu kabukların tümü doğal, masrafsız ve çevreye zararı olmayan biokütlelerdir. Buna ek olarak kullanılan kabukların gözenekli yapılarının olması, istenmeyen kimyasalları hapsederek çevreden uzaklaştırılabileceğine ve canlıların kısmen bu kimyasallardan korunabileceği laboratuvar ortamında çalışıldı. Yapılan deneyin FTIR spektrum sonuçlarına göre deney de kullanılan tüm doğal malzemeler adsorban olarak kullanılabilir olduğu, SEM sonuçlarına göre sipermetrinin bu doğal kabuklar tarafindan gözeneklerine hapsedilebileceği ve EDS analiz sonuçlarının da yapılan diğer analizlerle uyum içinde olduğu gösterilmiştir. Böylece çiftçiler yetiştirecekleri ürünleri ilaçlamadan önce toprak üzerine böyle doğal kabukları sererlerse, toprağa ve suya sipermetrinin taşınmasına engel olunabileceği deneysel olarak gösterildi.

\section{Teşekkür}

$\mathrm{Bu}$ çalışmanın deneysel aşamasının gerçekleşmesinde desteklerini esirgemeyen Prof. Dr. Belgin TUNALI ve Dr. Öğr. Üyesi Neslihan KAYA KINAYTÜRK'e çok teşekkür ederim.

\section{Yazarların Katkısı}

Konuyla ilgili tüm çalışma Deniz TÜRKÖZ ALTUĞ tarafindan gerçekleştirilmiştir.

\section{Çıkar Çatışması Beyanı}

Yazarlar arasında herhangi bir çıkar çatışması bulunmamaktadır.

\section{Araştırma ve Yayın Etiği Beyanı}

Yapılan çalışmada araştırma ve yayın etiğine uyulmuştur.

\section{Kaynaklar}

[1] Altıkat A., Turan T., Ekmekyapar Torun F. 2009. Türkiye'de Pestisit Kullanımı ve Çevreye Olan Etkileri. Atatürk Üniversitesi Ziraat Faültesi Dergisi, 40 (2): 87-92.

[2] Hernández A.F., Parrónb T., Tsatsakis A.M., Requena M., Alarcón R., López-Guarnido O. 2013. Toxic effects of pesticide mixtures at a molecular level: Their relevance to human health. Toxicology, 307: 136-145.

[3] Alavanja M.C., Hoppin J.A., Kamel F. 2004. Health Effects of Chronic Pesticide Exposure: Cancer and Neurotoxicity. Annual Review of Public Health, 25: 155-197.

[4] Huang J., Qiao F., Zhang L., Rozelle S. 2000. Farm Pesticide, Rice Production and Human Health. CCAP's Project Report, 1-54.

[5] Konstantinou I.K., Hela D.G., Albanis T.A. 2006. The status of pesticide pollution in surface waters (rivers and lakes) of Greece. Part I. Review on occurrence and levels. Environmental Pollution, 141: 555-570.

[6] Papadakis E., Papadakis N.Z., Kotopoulou A., Kintzikoglou K., Makris K.C., PapadopoulouMourkidou E. 2015. A pesticide monitoring survey in rivers and lakes of northern Greece and its human and ecotoxicological risk assessment. Ecotoxicology and Environmental Safety, 116: 1-9. 
[7] Satiroff J.A., Satiroff T.L., Mittelstet A.R., Snow D.D. 2021. Pesticide occurrence and persistence entering recreational lakes in watersheds of varying land use. Environmental Pollution, 273 (116399): 1-11.

[8] Silva V., Mol H.G., Zomer P., Tienstra M., Ritsema C.J., Geissen V. 2019. Pesticide residues in European agricultural soils-A hidden realityunfolded. Science of the Total Environment, 653: 1532-1545.

[9] Stolte J., Tesfai M., Oygarden L., Kvaerno S., Keizer J., Verheijen F., Panagos P., Ballabio C., Hessel R. 2016. Soil threats in Europe: Status, methods, drivers and effects on ecosystem services. JRC Science Hub, 1-206.

[10] Garoiaz H., Berrabah M., Elidrissi A., Hammouti B., Ríos A. 2012. Analysis of cypermethrin residues and its main degradation products in soil and formulation samples by gas chromatography-electron impact- mass spectrometry in the selective ion monitoring mode. International Journal of Environmental Analytical Chemistry, 92 (12): 1378-1388.

[11] Armenta S., Quintas G., Garrigues S., Guardia M. de la. 2005. A validated and fast pro-cedure for FTIR determination. Talanta, 67: 634-639.

[12] Turkoz Altug D., Kaya Kinayturk N., Tunali B. 2020. The use of pumice to prevent penetration of cypermethrin into the soil. Fresenius Environmental Bulletin, 29 (12 A): 11266-11272.

[13] Shukla Y., Yadav A., Arora A. 2002. Carcinogenic and cocarcinogenic potential of cypermethrin on mouse skin. Cancer Letters, 182: 33-41.

[14] Yıldız A. 2014. Aktive edilmiş ceviz kabuğuna boyar madde adsorpsiyonu. Yüksek Lisans Tezi, Bozok Üniversitesi, Fen Bilimleri Enstitüsü, Yozgat.

[15] Kanca A. 2019. Pamuk Atığı, Fındık Kabuğu ve Ceviz Kabuğu'nun Piroliz ve Oksidasyon Davranışlarının Kıyaslanması. Kocaeli Üniversitesi Fen Bilimleri Dergisi, 2 (2): 43-54.

[16] Tang R., Dai C., Li C., Liu G.W.S., Wang C. 2017. Removal of Methylene Blue from Aqueous Solution Using Agricultural Residue Walnut Shell: Equilibrium, Kinetic, and Thermodynamic Studies. Hindawi Journal of Chemistry, 2017 (8404965): 1-10.

[17] Li Z., Hanafy H., Zhang L., Sellaoui L., Netto M.S., Oliveira M.L., Seliem M.K., Dotto G.L., Bonilla-Petriciolet A., Li Q. 2020. Adsorption of congo red and methylene blue dyes on an ashitaba waste and a walnut shell-based activated carbon from aqueous solutions: Experiments, characterization and physical interpretations. Chemical Engineering Journal, 388 (15-124263): 110.

[18] Orue A., Eceiza A., Arbelaiz A. 2020. The use of alkali treated walnut shells as filler in plasticized poly (lactic acid) matrix composites. Industrial Crops and Products, 145 (111993): 1-9.

[19] Hemmati F., Jafari S.M., Kashaninejad M., Motlagh M. 2018. Synthesis and characterization of cellulose nanocrystals derived from walnut shell agricultural residues. International Journal of Biological Macromolecules, 120 (6): 1216-1224.

[20] Demirbas E., Dizge N., Sulak M., Kobya M. 2009. Adsorption kinetics and equilibrium of copper from aqueous solutions using hazelnut shell activated carbon. Chemical Engineering Journal, 148 (2-3): 480-487.

[21] Zhao B., Xu X., Zeng F., Li H., Chen X. 2018. The hierarchical porous structure bio-char assessments produced by co-pyrolysis of municipal sewage sludge and hazelnut shell and $\mathrm{Cu}$ (II) adsorption kinetics. Environmental Science and Pollution Research, 25: 19423-19435.

[22] Demirbaş Ö., Karadağ A., Alkan M., Doğan M. 2008. Removal of copper ions from aqueous solutions by hazelnut shell. Journal of Hazardous Materials, 153 (1-2): 677-684.

[23] Boumchita S., Lahrichi A., Benjelloun Y., Lairini S., Nenov V., Zerrouq F. 2017. Application of Peanut shell as a low-cost adsorbent for the removal of anionic dye from aqueous solutions. Journal of Materials and Environmental Science, 8 (7): 2353-2364.

[24] Xu T., Liu X. 2008. Peanut Shell Activated Carbon: Characterization, Surface Modification and Adsorption of $\mathrm{Pb} 2+$ from Aqueous Solution. Chinese Journal of Chemical Engineering, 16 (3 June): 401-406.

[25] Georgin J., Dotto G.L., Mazutti M.A., Foletto E.L. 2016. Preparation of activated carbon from peanut shell by conventional pyrolysis and microwave irradiation-pyrolysis to remove organic dyes from aqueous solutions. Journal of Environmental Chemical Engineering, 4 (1): 266-275. 
[26] Taşar Ş., Kaya F., Özer A. 2014. Biosorption of lead (II) ions from aqueous solution by peanut shells: equilibrium, thermodynamic and kinetic studies. Journal of Environmental Chemical Engineering, 2 (2): 1018-1026.

[27] Segal-Rosenheimer M., Dubowski Y. 2007. Heterogeneous ozonolysis of cypermethrin us-ing real-time monitoring FTIR techniques. The Journal of Physical Chemistry C, 111: 11682-11691.

[28] Altürk S., Tamer O., Avc1 D., Atalay Y. 2015. Synthesis, spectroscopic characterization, second and third-order nonlinear optical properties, and DFT calculations of a novel $\mathrm{Mn}$ (II) complex. Journal of Organometallic Chemistry, 797: 110-119.

[29] Mistry B. 2009. A Handbook of Spdectroscopic Data Chemistry. Oxford Book Company, 1-242.

[30] Kaya N., Kartal Z., Bahçeli S. 2012. FT-IR Spectroscopic Investigation of Some M(Benzyl Chloride $)_{2} \mathrm{Ni}(\mathrm{CN})_{4}$ Complex $(\mathrm{M}=\mathrm{Co}, \mathrm{Ni}$ and $\mathrm{Cd})$. Dumlupınar Üniversitesi, Fen Bilimleri Enstitüsü Dergisi, 27 (Nisan): 23-34. 